\author{
0. В. Володина 1
}

1 Петрозаводский государственный университет, 185910, Россия, Петрозаводск, пр. Ленина, 33

\author{
Сведения об авторе: \\ Володина Ольга Васильевна \\ e-mail: volodina@petrsu.ru \\ SPIN-код РИНЦ: 8293-3249 \\ (C) Автор (2019). \\ Опубликовано Российским \\ государственным педагогическим \\ университетом им. А. И. Герцена.
}

Аннотация. Интеллектуализация образовательного процесса в высшей школе, нацеленная на становление конкурентоспособного профессионала, обладающего интегрированной системой знаний, интеллектуальных умений и навыков, формирование общечеловеческих, гуманных качеств личности будущего специалиста, востребованного на рынке труда, готового активно и деятельно участвовать в наукоемких производствах и инновационных проектах, происходит в пространстве субъектно-субъектных и субъектно-объектных взаимоотношений и интеллектуальной деятельности студентов и преподавателей в широком контексте всех образовательных дисциплин, в том числе иностранного языка. Становление интеллектуальной культуры личности обучающихся педагогических направлений подготовки бакалавриата охватывает как рациональную сферу, предполагающую способность к формированию понятий, суждений и умозаключений, так и иррациональную - чувства, ощущения, интуицию, эмоционально-волевые проявления обучающихся. В методике обучения иностранному языку реализация концепции эмоционального интеллекта связана со значимой ролью эмпатии, саморегуляции, мотивации достижения, рефлексии и т.д. в формировании иноязычной коммуникативной компетенции обучающихся. Эмоциональный интеллект в процессе иноязычного образования обеспечивает удовлетворение таких базовых потребностей как а) потребность в защищенности (безопасности) посредством установления, принятия и признания ценности и значимости другого человека, выражения словесных конструкций в качестве стимула и реакции на сказанное на иностранном языке, а также демонстрации позитивных, эмоционально окрашенных проявлений невербальных форм взаимодействия, сенсомоторных реакций как показателей понимания в иноязычном общении; б) потребность в познании, связанной с желанием узнать и освоить новую информацию, возникающего с момента начала общения, первоначального контакта в процессе взаимодействия как проявления импринтинга ситуации, активизирующего мотивацию общения и дальнейшее развития коммуникативных навыков и умений как средства социализации обучающихся, и в результате достижения понимания между участниками обеспечивающего удовлетворенность процессом и результатом общения, чувство безопасности и развития компонентов эмоционального интеллекта как невербальных аспектов познания. Синтез умений самопонимания, саморегуляции и управления эмоциональным поведением в процессе общения и взаимодействия на иностранном языке как интегративное проявление эмоционального интеллекта обучающихся позволяет раскрыть потенциал и определить перспективу дальнейшего комплексного развития языковых навыков и речевых умений в ситуациях межличностного общения, когнитивного и эмоционального компонентов интеллектуальной культуры личности будущих учителей.

Ключевые слова: иноязычное образование, интеллектуальная культура, эмоциональный интеллект, память, общение, образовательная среда. 


\title{
The development of emotional intelligence through foreign language education as a condition for the formation of personal intellectual culture of future teachers
}

\author{
O. V. Volodina ${ }^{1}$ \\ 1 Petrozavodsk State University, \\ 33 Lenina Ave., Petrozavodsk 185910, Russia
}

\author{
Author: \\ Volodina Olga $\mathbf{V}$. \\ e-mail: volodina@petrsu.ru \\ SPIN: 8293-3249 \\ Copyright: \\ (C) The Author (2019). \\ Published by Herzen State \\ Pedagogical University of Russia.
}

\begin{abstract}
The intellectualisation of the educational process during secondary school years is directed towards developing a competitive professional with an integrated system of knowledge and intellectual skills that are in demand in the labour market and who is ready to actively participate in high-tech industries and innovative projects. This individual must also be equipped with the universal, humanistic characteristics of a future specialist. Such a process takes place in the space of subject-subject and subject-object relationships and intellectual activity on the part of students and teachers in the broad context of all educational disciplines, foreign language being one of them. The formation of undergraduate pedagogy students' intellectual culture includes both the rational aspect, i.e., the ability to form
\end{abstract} concepts, judgments and inferences, and the irrational one, i.e., students' feelings, sensations, intuition, and emotional expressions. In the methodology of foreign language teaching the implementation of the concept of intellectual intelligence is associated with the significant role of empathy, self-regulation, achievement motivation, reflection in the formation of students' foreign language communicative competence. Emotional intelligence in the process of foreign language education ensures the satisfaction of such basic needs as a) the need for security (safety) by establishing and recognising the value and importance of the other person, expressions and verbal constructions as a stimulus and response expressed in a foreign language, and also demonstrating positive, emotive manifestations of non-verbal forms of interaction with sensorimotor reactions as indicators of understanding in foreign language communication; b) the need for knowledge related to the desire for learning and mastering new information that begins with communication. This learning stems from initial contact in the process of interaction as a manifestation of the imprinting situation, activates motivation, communication and further development of communicative skills as a means of socialisation. It likewise is the result of reaching understanding between participants to ensure satisfaction with the process and result of communication. These all promote a sense of security and development with respect to emotional intelligence as non-verbal aspects of cognition. Synthesis of skills of self-understanding, self-regulation and management of emotional behaviour in the process of communication and interaction in a foreign language as an integrative manifestation of emotional intelligence of students permits students' potential to emerge and to determine the prospect of further comprehensive development of language skills and speech skills in situations of interpersonal communication as well as the cognitive and emotional components of the intellectual culture of future teachers.

Keywords: foreign language education, intellectual culture, emotional intelligence, memory, communication, educational environment.

Интеллектуализация образовательного процесса в высшей школе, нацеленная на становление конкурентоспособного про-

фессионала, обладающего интегрированной системой знаний, интеллектуальных умений и навыков, формирование общече- 
ловеческих, гуманных качеств личности будущего специалиста, востребованного на рынке труда, готового активно и деятельно участвовать в наукоемких производствах и инновационных проектах, происходит в пространстве суъектно-субъектных и субъектно-объектных взаимоотношений и интеллектуальной деятельности студентов и преподавателей в широком контексте всех образовательных дисциплин, в том числе иностранного языка. Интеллектуализация иноязычного образования предполагает целенаправленную, систематизированную установку процесса обучения иностранному языку на раскрытие интеллектуальных способностей обучающихся и формирование интеллектуальной культуры как способа интеллектуального взаимодействия в социокультурном пространстве межъязыкового и межкультурного взаимодействия и общения.

Становление интеллектуальной культуры личности обучающихся педагогических направлений подготовки бакалавриата, развитие мыслительных способностей, в том числе критического мышления, в контексте иноязычного образования охватывает как рациональную сферу, предполагающую способность к формированию понятий, суждений и умозаключений, так и иррациональную - чувства, ощущения, интуицию, эмоционально-волевые проявления обучающихся. В методике обучения иностранному языку реализация концепции эмоционального интеллекта связана со значимой ролью эмпатии (осознанного сопереживания текущего эмоционального состояния другого), саморегуляции (осмысленным и системно организованным управлением психоэмоциональными состояниями), мотивации достижения (стремлением к успеху, потребности добиваться желаемого и избегать неудач), рефлексии (критического самоанализа, понимания собственных мыслей и чувств, обращения внимания субъекта на свое сознание, переосмысление и переоценка личных достиже- ний) и т.д. в формировании иноязычной коммуникативной компетенции обучающихся.

Общепринятое понимание интеллекта не охватывает аспекты, связанные с управлением эмоциями и установлением эмоциональных связей с другими людьми, однако, как правило, именно эти свойства личности обусловливают успешность человека в социальном взаимодействии. Эмоциональный интеллект проявляется в способности быть приятным и обаятельным в общении, в умении улавливать настроения и желания собеседников, видеть их сильные и слабые стороны, ориентироваться в происходящей ситуации, быть стрессоустойчивым, оказывать воздействие на характер взаимодействия и ход событий под влиянием интуитивно воспринимаемых нюансов. Эмоциональный интеллект отражает способность анализировать, изучать, перерабатывать информацию, имеющую эмоциональный окрас, т. е. устанавливать смысл и важность конкретных эмоциональных переживаний, их взаимосвязь и взаимообусловленность, применение эмоционально насыщенных сведений для формирования оснований и начал мыслительных процессов, идентификации альтернатив и выбора наиболее приемлемых вариантов принятия решений.

Эмоциональный интеллект представляет собой иерархически упорядоченные, поэтапно формируемые в онтогенезе составляющие, относящиеся как к собственным эмоциям человека, так и эмоциям других людей: а) идентификация эмоций предполагает восприятие эмоций, умение отметить наличие факта переживания определенного эмоционального состояния, почувствовать свои эмоции и другого человека, определять, сопоставлять, классифицировать, различать подлинные чувства и имитацию, фальсификацию истинных проявлений чувств и эмоций; б) направленность эмоций на выполнение интеллектуальных действий связана с использованием эмоций для увеличения результативности мысли- 
тельных процессов, ориентированностью на конкретные значимые факты и события, актуализацией и стимулированием эмоций, содействующих эффективному решению проблем, например, вдохновение и хорошее настроение помогают в развитии и воплощении творческих идей, а сомнения, недоверие, колебания, скептицизм как проявления критического мышления могут выступать отправным началом и средством всестороннего разбора и анализа разнообразных взглядов на рассматриваемый вопрос; в) понимание отдельных и комплексных эмоциональных состояний и процессов, умение отметить и объяснить смену эмоций, переход одного чувства в другое, осмысление причинных факторов эмоциональных переживания, вербальное описание переживаний, чувств, эмоционально обусловленных мыслей и поведения; г) контроль $и$ управление эмоциями как свойство человека наблюдать за своим эмоциональным поведением, психофизиологическим процессом, отражающим субъективную значительность предметов и событий, их отражение в сознании в форме переживаний; умение снижать напряженность и интенсивность воздействия отрицательных эмоций, осмысливать причины и последствия неприятных переживаний, готовность к преодолению стрессовых ситуаций без нивелирования сопутствующих эмоций для дальнейшего конструктивного анализа, содействующего самопониманию, саморазвитию, развитию и укреплению межличностных отношений.

Интеллектуализация иноязычного образования предполагает единство, взаимосвязь и взаимообусловленность интеллектуального и аффективного компонентов личности, познавательных и эмоциональных процессов, когнитивных возможностей и эмоциональных переживаний для стимулирования воздействия эмоций на свойства памяти обучающего, когнитивных способ- ностей по накоплению, сохранению и воспроизведению воспринятых, пережитых и осмысленных знаний, впечатлений, опыта. Взаимосвязь и взаимозависимость эмоциональных процессов и процессов памяти проявляется в следующих аспектах: а) успешность и результативность восстановления информации из памяти обеспечивается идентичностью эмоциональных состояний человека в момент кодирования, заучивания и припоминания, воспроизведения; б) зависимость эмоционального состояния в момент воспроизведения от эмоциональной окрашенности и насыщенности воссоздаваемого материала; в) влияние эмоциональных переживаний в процессе кодирования материала в памяти на обогащение эмоциональной палитры содержания запоминаемого материала. Закрепление в памяти эмоционально насыщенного материала, соответствующего эмоциональным переживаниям человека, в процессе кодирования информации определяется как эффект конгруэнтности. Выраженность данного эмоционального состояния в процессе переработки и кодирования информации свидетельствует об уровне взаимодействия и взаимовлияния эмоций, памяти и когнитивных процессов.

Психолого-педагогическими условиями развития как эмоциональной сферы, так и иноязычной коммуникативной компетенции обучающихся в процессе обучения иностранному языку в вузе являются ситуации общения, диалоговые модели речевого взаимодействия на иностранном языке, соответствующие совокупности необходимых требований формирования безопасной и познавательной эмоционально-положительной образовательной среды. Общение на иностранном языке закладывает основы и укрепляет эмоционально-энергетические связи во взаимоотношениях, способствующие установлению и укреплению открытости, доброжелательности, искренности, до- 
верия к другому человеку, уверенности в себе, позитивной оценки собственных навыков и способностей. Эмоциональный интеллект в процессе иноязычного образования обеспечивает удовлетворение таких базовых потребностей как а) потребность 8 защищенности (безопасности) посредством установления, принятия и признания ценности и значимости другого человека, выражения словесных конструкций в качестве стимула и реакции на сказанное на иностранном языке, а также демонстрации позитивных, эмоционально окрашенных проявлений невербальных форм взаимодействия, сенсомоторных реакций как показателей понимания в иноязычном общении; б) потребность в познании, связанная с желанием узнать и освоить новую информацию, возникающим с момента начала общения, первоначального контакта в процессе взаимодействия как проявления импринтинга ситуации, активизирующего мотива- цию общения и дальнейшее развития коммуникативных навыков и умений как средства социализации обучающихся, и в результате достижения понимания между участниками, обеспечивающего удовлетворенность процессом и результатом общения, чувство безопасности и развития компонентов эмоционального интеллекта как невербальных аспектов познания. Синтез умений самопонимания, саморегуляции и управления эмоциональным поведением в процессе общения и взаимодействия на иностранном языке как интегративное проявление эмоционального интеллекта обучающихся позволяет раскрыть потенциал и определить перспективу дальнейшего комплексного развития языковых навыков и речевых умений в ситуациях межличностного общения, когнитивного и эмоционального компонентов интеллектуальной культуры личности будущих учителей. 